\title{
Project-oriented laboratory courses in optics education
}

Charles Joenathan, Robert Bunch, Azad Siahmakoun

Charles Joenathan, Robert M. Bunch, Azad Siahmakoun, "Project-oriented laboratory courses in optics education," Proc. SPIE 2525, 1995 International Conference on Education in Optics, (13 October 1995); doi: $10.1117 / 12.224019$

SPIE Event: SPIE's 1995 International Symposium on Optical Science, Engineering, and Instrumentation, 1995, San Diego, CA, United States 


\title{
PROJECT ORIENTED LABORATORY COURSES IN OPTICS EDUCATION
}

\author{
C. Joenathan, R. M. Bunch and A. Siahmakoun \\ Department of Physics and Applied Optics \\ Rose-Hulman Institute of Technology \\ 5500 Wabash Avenue \\ Terre Haute, IN 47803, USA
}

\begin{abstract}
:
In this paper we discuss the implementation of a project oriented laboratory course in optics education. Through our discussion we show the relevance and necessity for such a course. The course is tailored not only to make the students to learn concepts, but to build a product from scratch to completion. Emphasis is also made on the design, performance, marketing and aesthetics of the product.
\end{abstract}

Key words: optics education

\subsection{INTRODUCTION}

Optics is interdisciplinary in nature with applications covering a broad range of fields. Although optics originated from physics it has evolved into a field that is a mixture of physics and engineering. In this context the method of teaching and even the learning styles of the students are different from conventional physics students. Therefore, optics courses are usually a blend of new technology, engineering and physics. However, the traditional sequence in a course is to have a laboratory associated with the course or even a stand alone laboratory course. Laboratory experiences provide the tool for understanding the basic ideas but do not necessarily provide the background for the students to be prepared to go to industry.

At Rose-Hulman Institute of Technology (RHIT) the students that graduate and take up jobs and also the students who enter graduate school have often expressed their lack of experience of designing and building a product. Even though a capstone course such as Advanced Optics Laboratory did provide some necessary insight into research and understanding concepts, it failed to create enthusiasm in the students. The course was offered during the spring quarter of the senior year so any additional system oriented experience modeling the work environment would not provide the students with background that would help them in their job search. Therefore it became apparent that some new sequence of courses or a new course had to be designed that would provide the knowledge and experience. The new project oriented laboratory course designed at Rose-Hulman Institute of Technology meets the concerns and needs from both the students and teachers point of view. This paper will discuss the organization of the course, some projects examples given to the students, the goals given to the students and the accomplishments, the responses, and the products developed. We 
also discuss other optics courses in the applied optics curriculum at Rose-Hulman to show how the project lab complements the other laboratory oriented course.

\subsection{BACKGROUND}

Rose-Hulman Institute of Technology is primarily an undergraduate science and engineering institution although we have an active masters level graduate program in many areas. Courses of study leading to bachelor degrees are: Applied Optics, Chemistry, Chemical Engineering. Civil Engineering, Computer Science, Electrical Engineering, Mechanical Engineering, Mathematics and Physics. The Department of Physics and Applied Optics offers B.S. degrees in Applied Optics and in Physics and M.S. degree in Applied Optics. No Ph.D. degrees are offered by the Institute. The Applied Optics program at Rose-Hulman was initiated in $1985^{1}$, and realizing the importance of optical measurement and testing, courses such as PH395 Optical instrumentation and testing and PH494 fiber optics and application were incorporated. These courses address some aspects of measurement and testing. However, to enrich the Applied Optics curriculum three new courses was recently introduced: PH415 Applied Optics Projects Lab I, PH416 Applied Optics Projects Lab II and PH495 Optical Metrology. In addition, the Center for Applied Optics Studies, an industrial outreach arm of the institute, has several projects related to optical measurement and testing. Some projects accomplished with undergraduate and graduate students are: Fiber optic right angle connectors, fiber optic interferometric sensor, fiber-optic electronic speckle pattern interferometer, fiber optic core and cladding diameter measurement, aging of biological specimen using laser speckles, and probing of the chest wall expansion using holographic interferometry. Some of the projects assigned to the teams in the project oriented course come directly from the Center for Applied Optics Studies.

Table 1 gives the sequence of optics courses taken by the Applied Optics majors to fulfill the requirement for the degree. This table also shows the background knowledge of the students who take PH415 and 416 project oriented courses. As one can see, this program is laboratory intensive ${ }^{2}$, where the alphabet ' $\mathrm{L}$ ' within brackets indicate courses with laboratory. It should be noted that PH395 Optical Instrumentation and Testing course is a laboratory intensive course with two lectures per week and 2 three-hour lab periods. Besides these courses there are graduate level optics courses the students can take. Further, PH450, PH494, PH495, and PH485 are three hour lectures a week and with eight laboratory experiments each of 3-hour duration.

\subsection{PREVIOUS LAB COURSE}

In the past, a 4-credit laboratory intensive course at the end of the spring of the senior year was the capstone course for the Applied Optics majors. In this class several research projects are assigned as laboratory experiments. The course was usually team-taught by four or five faculty members. Most of the experiments are advanced and cover topics at the forefront of research in a particular field. The students spend two weeks on one experiment. The response from the students for this course was the lack of providing them with sufficient material ahead of time and the structure followed the other optics laboratory. As the course was offered during the spring quarter of the senior year, any additional system oriented experience modeling the work environment did not provide the students with background to help them in their job search. 
Freshman Year

Spring Term

PH170 Intr. Opt. and Appln................. 2

Sophomore Year

Winter Term

PH 292 Physical Optics (L)....................4

Spring Term

PH 280Paraxial Optics(L)....................4

Junior Year

Fall Term

PH 380 Lens Design and Aberrations(L)...4

Winter Term

PH 392Coherent Wave Optics.
PH 395Opt. Inst. \& Tstg (L).................4

Spring Term

PH 415Applied Optics Proj. Lab I...........2

PH 450Laser Physics \& Appln.(L)...........4

Senior Year

Fall Term

PH 416Appl. Optics Proj. Lab II.............2

PH 4950ptical Metrology (L)................4

Winter Term

PH 494Fiber Optics \& Appln (L)............4

Spring Term

PH 485Electro-Optics (L)

Table 1: The optics courses offered by the Department of Physics and Applied Optics.

\subsection{CURRENT PROJECT COURSE}

The single 4-credit Advanced Optics Lab course has now been replaced with two separate courses, PH415 and 416 each two-credits and are currently being taught in the spring quarter of the junior year and fall quarter of the senior year for Applied Optics majors. These courses emphasize hands on experience for the students who take up projects and build a product. Significantly, students not only learn to be part of the project team but find many intelligent solutions to problems in their design. In this course the students will use their optics background to design, test, and construct a prototype optical part, component, or a system. Usually the projects given to the students are carefully chosen so that the given project can be completed within the allotted time that is one quarter. Not only the project will have to be design oriented, they also will have to challenging. Based on the experience they have gained in PH415, the students feel confident with the PH416 course. A four-hour lab period is provided to the students every week when the faculty adviser is available for discussion and assistance. The students work in teams of two and sometimes in groups of three. The students in each team are chosen by the faculty involved in the course. Each team will have the assistance of either one or two faculty members.

The selection of individual students that comprise a team is based on the student's ability and compatibility. Then the teams are provided with a statement of work and with some lead articles related to the project. The time allotted to the reply to the statement of work is usually two weeks. Two examples of statement of work given to the students are presented in table 2.

The students respond to this statement of work with a suitable proposal after searching the literature or relevant text books to find the method they feel is a suitable response to the statement 
Project \#1

Laser Beam Collimation Tester using Spiral Gratings ${ }^{3}$

Statement of Work:

Design and construct a prototype laser beam collimation testing system using spiral grating techniques.

Design Requirements:

1. Must differentiate between incident converging and diverging laser beams.

2. Must be as compact as possible.

Deliverables:

1. Computer program/procedure to generate spiral gratings with various pitch.

2. Prototype laser beam collimation test system.

3. List of specifications of the system.

\section{Project \#2}

Rough Surface Interferometer for Flatness Measurement ${ }^{4}$

\author{
Statement of Work: \\ Design and construct a prototype \\ interferometer that measures the flatness of \\ rough surfaces.
}

Design Requirements:

1. Must be capable of testing flatness of machined aluminum surfaces.

2. Must be compact and portable.

Deliverables:

1. Prototype interferometer test system.

2. Instrument must be calibrated.

3. List of specifications of the system.

Table 2: Examples of the statement of work given to students.

of work. Sometimes relevant materials are provided that gives guidelines for their search. One of the advantages of this literature search is that the students learn to go to the library and learn the method of searching for scientific articles. Further, the students learn to read scientific articles. Faculty advisers are asked to refrain from giving too much material. The proposal from each team in a memo format reply to the statement of work containing preliminary design and an outline plan for completion. The proposal should also include the method they have adopted, the time table of the work they intend to accomplish during the quarter, the parts and components needed for the project, and finally a suitable laboratory space to begin their work. This is done during the third week of the quarter. If the reply to the statement of work does not meet the requirement one additional week is provided to the teams and with more assistance. This is needed to have them successfully complete the project. The timetable of their work plan helps them to determine the time and effort needed during various stages of the project.

Each week the students submit a one page memo report of the work accomplished during the previous week, and a list of goals to be accomplished during the next week. This helps both the faculty advisers as well the team members access where they are in the outline plan. At each weekly meeting a representative from every group will give a short presentation (usually for $10 \mathrm{~min}$.) on the project's progress to date, the activities of the group on the project during the last week, and 
the work to be done on the project during the next week. Group members alternate giving this presentation so that every student gets an opportunity to participate.

A midterm progress report describing all the work accomplished at that point is turned in by the students for evaluation. Each team is responsible for giving a final presentation detailing the results of their project and demonstrating their prototype. Importance is given to the technical quality of the presentation but they will also be evaluated on oral communication skills. The prototype is evaluated on aesthetics, design, size, compactness, optomechanics, sophistication of any electronics, quality of tests, quality of the overall part/component/instrument in meeting or exceeding the design specifications. Finally they are also asked to present a reasonable estimate of the cost for producing a product of the prototype and of the expected sales price.

Each team submits a formal lab report on the results of their project. Formal lab reports generally follow the guidelines of the AIP Style Manual ${ }^{5}$. The project report is due at the time of the Prototype Presentation. The final examination for this course is an oral examination given to each individual student and evaluated by all the faculty involved in this course. This examination emphasizes the optics of the project but is not restricted to the project. The depth and breadth of understanding and comprehension of optics concepts are tested.

\section{$\underline{5.0}$ GRADING SCHEMES}

All projects are evaluated by all of the faculty involved in the course. The final grade is based on the following work individually performed by the students.

1. Reply to the Statement of Work.

2. Written List of Goals.

3. Weekly 10 Minute Oral Presentation.

4. Midterm Progress Report.

5. Prototype Presentation.

6. Project Report.

7. Oral Examination.

The grading of the memo format report is based on the data, presentation, analysis, conclusion, references, and the work for the next week. The final grade is mostly based on the prototype, project report and oral examination. In the oral examination all the faculty members involved in the project will evaluate the student responses to the specific questions asked.

\subsection{RESULTS AND CONCLUSION}

This course sequence is in its third year and a number of students have completed the project oriented laboratory course. In all the cases the projects were completed in one quarter. Even though it is a 2-credit course, the students spent a lot of time in the laboratory and as well as in the workshop. We observed great enthusiasm and pride in the students after the completion of the prototype. The reaction of the students to this course was overwhelming supportive. All the students 
reported that they learned the concepts better and realized the importance of the technical and industrial aspect of the project. Determining the market value of their product in comparison to other products in the industry was an eye opener both for the students and the faculty involved in the project. Some projects that have been successfully completed by the students are: a rough surface interferometer to measure flatness of machined parts, a fiber optic hand held telescope, a polarization rotator using mirrors, a collimation tester using spiral gratings, a holographic element collimation tester, a $35 \mathrm{~mm}$ slide projector, and a zoom lens for a CCD camera. In all these projects the students performed various measurement and testing tasks from laboratory equipment employed in other optics courses.

\subsection{ACKNOWLEDGEMENTS}

This work was supported in part by the National Science Foundation Laboratory Improvement Program grant \# DUE - 9350853. The authors would like to thank Dr. Wagner and Dr.Kolbert who have also been involved in teaching the project laboratory courses.

\subsection{REFERENCES}

1. B. M. Khorana, "Birth and evolution of a new optics degree program", SPIE, 978, 21-22 (1988)

2. R. M. Bunch, "Development of instructional optics laboratory", SPIE, 978, 52-55 (1988)

3. Chon-wen Chang and Der-Chin Su, "Collimation method that uses spiral gratings and Talbot interferometry", Optics Letters, 16, 1783-1784, (1991)

4. N. Abramson, "The 'interferoscope' a new type of interferometer with variable fringe separation," Optik, 30, 56-71 (1973)

5. AIP Style Manual 3rd ed., edited by D. Hathwell and A.W.K. Matzner, Am. Inst. Phys., New York, (1978) 